\title{
Effects of fisheries on ecosystems: just another top predator?
}

\author{
A. W. TRITES, V. CHRISTENSEN AND D. PAULY
}

Apex predators - such as pinnipeds, cetaceans, seabirds and sharks - are constrained by the sizes of prey they can consume and thus typically feed within a narrow range of trophic levels. Having co-evolved with their prey, they have influenced the behaviours, physiologies, morphologies and lifehistory strategies of the species they target. In contrast, humans can consume prey of any size from all trophic levels using methods that can rapidly deplete populations. On an ecological time scale, fisheries, like apex predators, can directly affect the abundance of other species by consuming or outcompeting them; alternatively they can indirectly affect the abundance of non-targeted species by removing other predators. However, there is growing evidence that the effects of fisheries go well beyond those imposed by apex predators. Theory and recent observations confirm that the continued development and expansion of fisheries over the past half century has led to a decrease in the size and life spans of targeted species, with reproduction of fish occurring at earlier ages and at smaller sizes. In addition, high levels of fishing have altered the makeup of many ecosystems, depressing the average trophic level of heavily fished ecosystems and speeding up the rate of nutrient turnover within them. Inevitable consequences of fishing down the food web are increased ecosystem instability, unsustainable fisheries and an inability for the ecosystem to support healthy, abundant populations of apex predators.

Outside of a general appreciation that fishing can directly reduce the numbers of targeted and non-targeted (by-caught) species, there appears to be little understanding of the effects that fishing can have on other species 
or on the ecosystem as a whole. This is due in part to the inherent spatial and temporal complexities associated with studying marine ecosystems, as well as the perceived expense and difficulties associated with monitoring and tracking changes and responses in complex systems. Fisheries can directly affect food webs by removing large numbers of targeted and bycaught species, and by having a physical impact on the habitat of benthic organisms through bottom trawling (Goni i998). Such direct effects of fisheries on food webs are relatively easy to document. The less intuitive effects of fisheries are those that are indirect. They include altered food-web interactions, increasing rates of nutrient turnover caused by discarded unwanted fish and organic detritus (offal), and continued mortality caused by lost gear (ghost fishing).

Faced with a paucity of data to assess indirect effects of fisheries, it is easy to be lulled into assuming that humans have no more effect on food webs than do other apex predators - whether they be sharks, sea lions, whales or birds. On some levels there are undoubtedly parallels between how fisheries and apex predators affect food webs, but on others the two groups are clearly subject to different controls and exert different forces on marine ecosystems.

Considerable advances have been made in recent years in compiling and analysing extensive fishery datasets and in developing mathematical descriptions of ecosystems. These tools provide significant insights into the direct and indirect effects of fisheries on ecosystems. They also provide a means for a better understanding of the roles that apex predators play in marine ecosystems and the ultimate role that fisheries play in influencing the dynamics of apex predators.

\section{DIRECT EFFECTS OF FISHING}

Humans have long had an association with the coastal regions of the world and can trace the expansion of civilization to the ready supply of fish, invertebrates and mammals that could be easily gathered, caught or hunted. Until relatively recently, human activities were restricted to the nearshore and surface waters. But all of this has changed over the past century as fossil fuels and the application of new technologies have allowed fisheries to move further from shore, to fish in deeper waters and to become more effective at finding and capturing species from all levels of the food chain (Botsford et al. I997, Merrett \& Haedrich I997, Hutchings 2000, Pauly et al. 2002, 2003).

The geographic and technical expansion of fisheries around the world through the early to late I9oos was mirrored by steady increases in world 


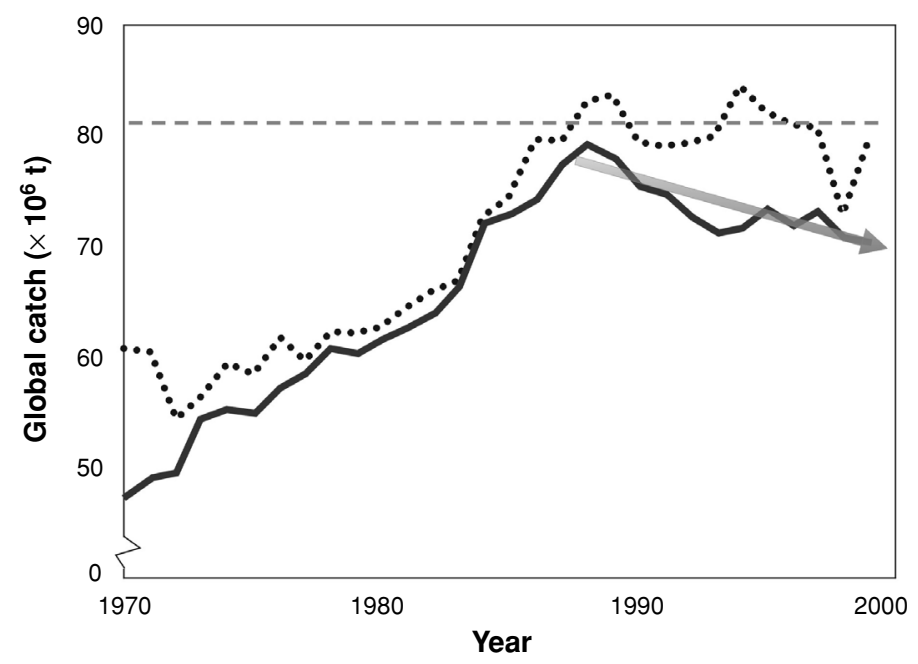

Fig. 2.I Global reported catch with (dotted line) and without (solid line) the Peruvian anchovy. Total world catches have fluctuated around 82 million tonnes since the late ig8os due to high catches of Peruvian anchovy which compensated for the global decline in landings of all other species combined. Adapted from Watson and Pauly (200I).

catches. However, global landings began stagnating in the early I980s, and have decreased since the late I980s (Watson \& Pauly 200I). This decreasing trend is particularly apparent when the widely fluctuating catch of Peruvian anchovy is discounted (Fig. 2.I).

Christensen et al. (2003b) reconstructed the biomass of commercially important fishes that were present in the North Atlantic around I900. They considered the abundances of high-trophic-level species such as tuna, sharks, mackerel, cod, flatfish and salmon - and relied on 23 spatialized ecosystem models and multiple regressions that considered environmental and biological factors to predict abundances over spatial resolutions of $\frac{I}{2} \times \frac{I}{2}$ degree latitudes and longitudes. Plotting the densities of fishes in the North Atlantic showed the relatively high productivity of the shelf regions of Europe and eastern North America (Fig. 2.2). However, the data also showed a major decline between 1900 and 1999 in the range and biomass of the top predatory fishes that are typically found on dinner tables. Biomass in the North Atlantic fell by 90\% during the twentieth century, leading to declines of catches throughout the North Atlantic, notably in eastern Canada (Fig. 2.2). Similar downward trends in the biomasses of high-trophiclevel fishes have been seen elsewhere in the world where they have been 


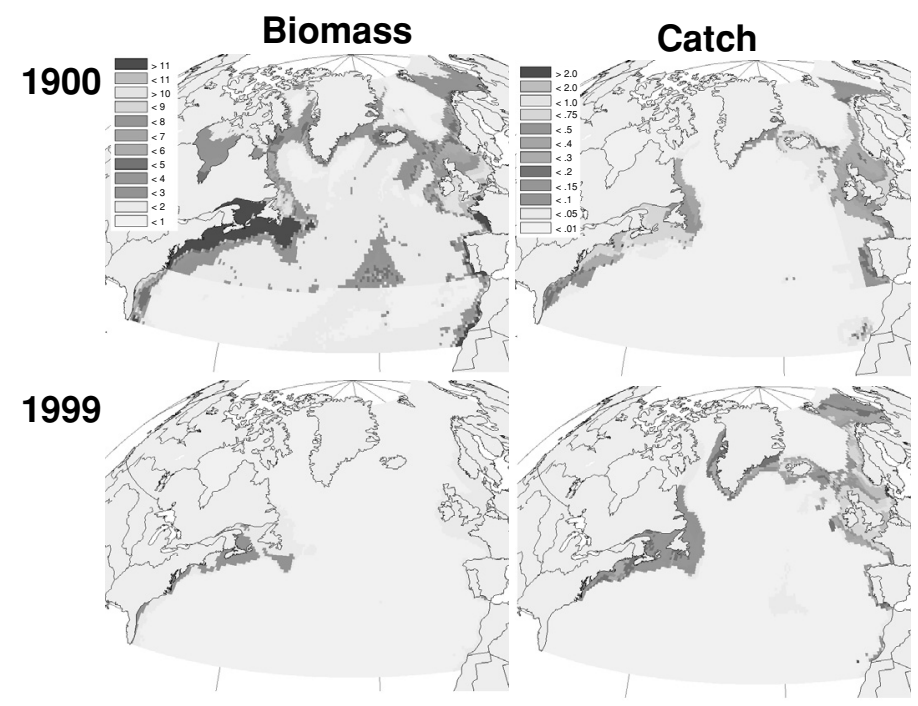

Fig. 2.2 Predicted biomass distributions and estimated fishing intensity for high-trophic-level fishes (trophic level $(\mathrm{TL}) \geq 3.75$ ) in the North Atlantic in I9०0 and I999. Legend indicates biomass in tonnes per square kilometre. Adapted from Christensen et al. (2003b).

investigated, such as northwest Africa or southeast Asia, where biomass declined as fishing intensity increased (Christensen et al. 2003a, 2004).

Although it appears to have taken less than a century for North Atlantic fisheries to reduce the biomass of the high-trophic-level fishes to under I0\% of their original amounts (Christensen et al. 2003b), declines were well underway before the advent of modern fishing technologies. The onceabundant populations of marine mammals, turtles and large fishes are believed to have incurred massive declines long before I900 (Jackson et al. 200I). However, the pace of change has quickened considerably in recent years to the point that industrial fleets may now only require a few decades to reduce all fish populations to Io\% of their unfished levels (Myers \& Worm 2003).

Overall, there has been a serial depletion of species from marine ecosystems (Pauly et al. 1998a, Jackson et al. 200I, Myers \& Worm 2003). Historically, fishing started at the top of most food chains by removing the larger, valuable and more easily caught species - then moved down to the nextbiggest species as those above were depleted and were no longer easy or economical to catch. The downward shift towards taking species from lower trophic levels is termed 'fishing down the food web' (Pauly et al. 1998a). 


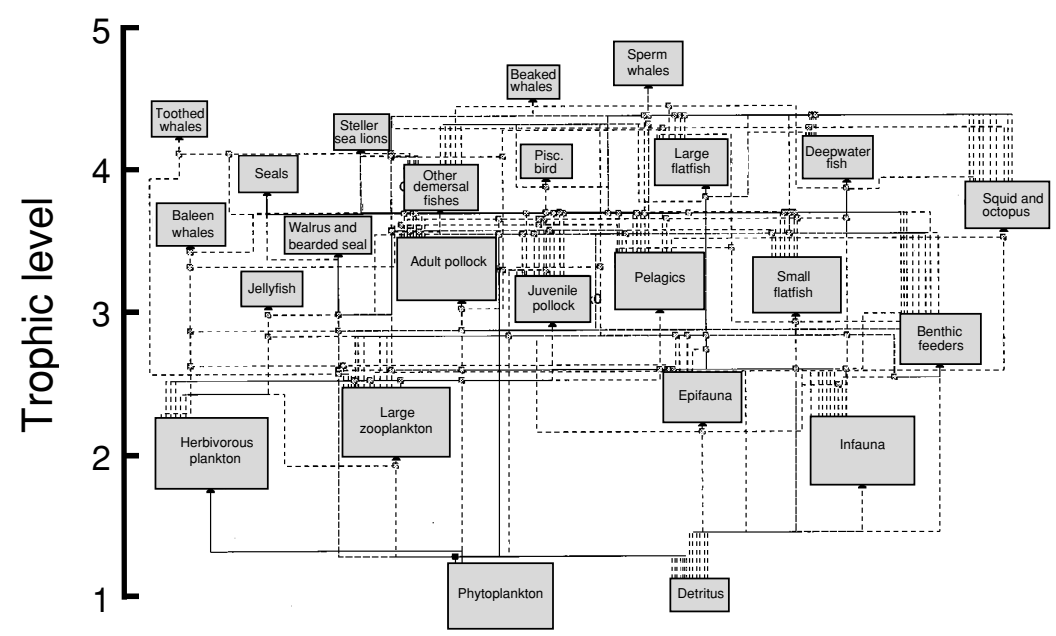

Fig. 2.3 An energy-flow, food-web description of the eastern Bering Sea highlighting the trophic level of each group of species and the relative strength of the interactions (based on the amount of energy flowing from producers and consumers). Here species or groups of species are placed according to their trophic level (calculated as I.o plus the mean trophic level of the species that they consume), and the size of each box is relative to the biomass of the species. In general, trophic levels of functional groups tend to cluster about integer values. Pisc., piscivorous. From Trites et al. (I999).

Trophic levels are the layers that make up food webs, wherein animals are ranked according to how many steps they are above the primary producers at the base of the food web (e.g. Fig. 2.3). Microscopic plants at the bottom are assigned a trophic level of $\mathrm{I}$, while the herbivores and detritivores that feed on the plants and detritus make up trophic level 2. Higherorder carnivores, such as most marine mammals, are assigned trophic levels ranging from 3 to 5 (Pauly et al. I998b, Trites 200I). Animals that feed from more than one trophic level have non-integer trophic levels. Thus, knowing what an animal eats is all that is needed to calculate its trophic level.

Pauly et al. (I998a) calculated the mean trophic level of reported catches and found that it had declined over the years. The sharpest declines were noted in the northwest Atlantic where the mean trophic level dropped from a peak of 3.7 in 1965 to 2.8 in 1997 . Smaller declines were noted in the northeast Atlantic and the Mediterranean Sea, and have been reported elsewhere as well (e.g. Arias-Gonzalez et al. 2004, Sanchez \& Olaso 2004). Overall, there has been an average worldwide trophic decline of o.I per decade in 


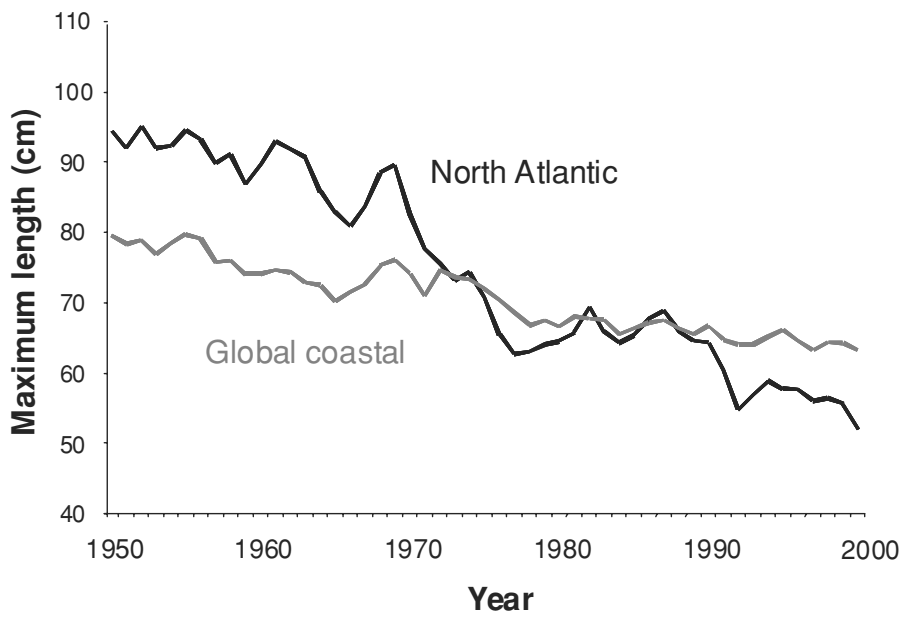

Fig. 2.4 Maximum length attained by species landed from I950 to 2000 . Adapted from R. Watson, unpublished data.

the mean trophic level of species caught since the I970s. The inevitable consequence of such a decline is that species from the lowest trophic levels may eventually become the mainstay of commercial fisheries.

In addition to progressively catching increasing numbers of species from lower trophic levels, there are also clear signs that the fish being caught are no longer as big as they once were. Globally, there has been about a $25 \%$ reduction in the mean maximum lengths of landed fish from coastal waters (Fig. 2.4). These trends reflect the increasing importance to fisheries of catching smaller species, as well as the selective forces of fisheries which are resulting in individual fish maturing at smaller sizes.

Reductions in size-at-age and age-at-maturation of commercially exploited fish have been reported in a number of ecosystems (Trippel I995, Rochet I998, Law 2000). On the Scotian Shelf in eastern Canada, for example, average weights of individual demersal fish have decreased by $4 \mathrm{I} \%$ to 51\% since the I970s (Zwanenburg 2000). Declines have also been reported in the sizes of large demersal fishes in other high-latitude regions, and have been detected in some - but not all - tropical regions (Pauly I980, Bianchi et al. 2000). Such changes in body sizes are particularly troubling, given that survival and reproduction are functions of body size (Reiss I989). Small fish generally incur higher mortality rates and produce fewer eggs than larger fish. Fisheries thus appear to have the potential to cause evolutionary changes based on the apparent phenotypic and genetic response of exploited species (Heino \& Godo 2002, Hutchings 2004, Olsen et al. 2004). 
Whether or not such effects of fisheries are long lasting or reversible is not known. However there are indications that genetic drift may compromise a population's recovery after severe depletion (Hutchinson et al. 2003).

The most obvious direct effect of fisheries on marine ecosystems has been reductions in the abundances of targeted species, such as cod on the east coast of Canada (Walters \& Maguire 1996). Less obvious has been declines in the spatial ranges and degrees of overlap of depleted targeted species with others in the ecosystem (e.g. Garrison \& Link 2000), as well as the potential losses of biodiversity (Agardy 2000). Losses of individuals through bycatch and ghost fishing are poorly documented, but are known to have directly affected many populations of the larger species such as seabirds, turtles and marine mammals. Entanglement in fishing gear or being caught and drowned by baited hooks have threatened a number of species (e.g. Tasker et al. 2000). Tuna and shrimp fisheries have also been responsible for large levels of bycatch of unwanted species, but the ecosystem effects of bycatch are less well documented or understood. Finally, there are the direct and immediate effects of bottom trawling that can modify benthic habitat and community structure (e.g. Koslow et al. 2000, Jennings et al. 200I), as well as severely decreasing benthic mega-fauna production (Hermsen et al. 2003).

\section{INDIRECT EFFECTS OF FISHING}

Considerable progress has been made in understanding the potential indirect effects of fishing through mathematical descriptions of ecosystems and the accessibility of ecosystem modelling software (e.g. Walters et al. I997, Christensen \& Walters 2004). A number of models have recently been constructed that provide insights into how fisheries might alter food-web interactions and increase the rates of nutrient turnover through discarded organic detritus (offal) and unwanted species (e.g. Christensen I998, Cox et al. 2002, Arias-Gonzalez et al. 2004). For example, simulation models of the eastern Bering Sea explored the ecosystem consequences of commercial whaling and catching groundfish; the models showed that removing whales had a small positive effect on groundfish by reducing competition for food, and that reducing fishery removals of cannibalistic adults reduced the amount of young pollock available for marine mammals to eat (Trites et al. I999, 2004). The models also revealed a high degree of potential competition between seals and large flatfish and adult pollock, as well as the large overlaps in the diets of pollock and baleen whales. Models have also been used to show the importance of icefish in the Antarctic ecosystem, 
as well as the possible consequences that catching increased amounts of krill might have on penguins and other species in the Antarctic ecosystem (Alonzo et al. 2003, Bredesen 2003). The models generally go far beyond the simple, single-species assessment of the effects of removing biomass, and have revealed unexpected effects of fishing through indirect food-web interactions.

Excessive catches of one species may lead to the collapse of an important predator or prey in the system and may cause changes in the growth and survival patterns of other species in the food web (Walters \& Kitchell 200I). Continued expansion of fisheries into deeper waters and the targeting and marketing of new species may increase competition with predators previously unaffected by fisheries, such as beaked whales and sperm whales. Changes at one level of a food web can also have cascading effects on others; for example in the Black Sea a trophic cascade is believed to have been launched by fishery removals of apex predators which caused planktivorous fish to increase, and led to a decline in zooplankton biomass that in turn allowed phytoplankton to increase (Daskalov 2002). This chain of events is thought to explain the explosions of phytoplankton and jellyfish reported in the Black Sea over the past 30 years (Daskalov 2002). In the Bering Sea, a similar sort of question has been posed over whether the removal of large baleen whales resulted in cascading declines of other species of marine mammals (Springer et al. 2003) or increases in flatfish and gadids (Trites et al. I999). Mathematical models provide a structured framework to test the consistency of trophic-cascade arguments and a means of gaining further insight into the possible unexpected effects of fishing on ecosystems.

Some groups of apex predators, such as marine mammals, may be affected by fisheries even when the prey and species caught do not overlap. This has been termed 'food-web competition' (Trites et al. 1997). It occurs at the base of the food pyramids and involves the primary production required to sustain these pyramids (Fig. 2.5). Food-web competition occurs when there is potential overlap of the trophic flows supporting a given group (such as marine mammals) with the trophic flows supporting another group (such as fisheries). The relationship between the size of fishery catches and the amounts of primary production required to sustain fisheries and marine mammals suggests that the primary production available to marine mammals may decline as catches increase (Trites et al. 1997). This raises the possibility that fisheries in some areas may have entered into 'food-web competition' with marine mammals. 


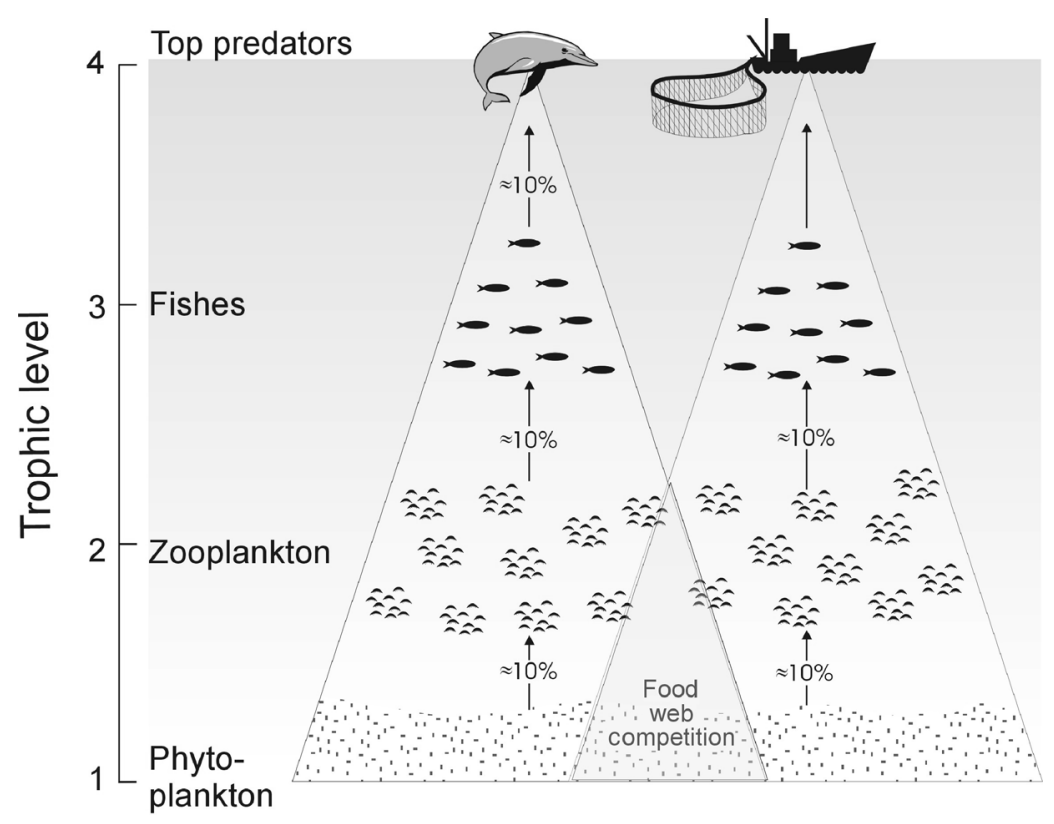

Fig. 2.5 Schematic of food-web competition, illustrating how marine mammals and fisheries may not directly compete (because they consume different species), but could indirectly compete through the primary production required to sustain each of their respective prey populations. Adapted from Trites et al. (1997).

Over the past 80 years, food-web research has sought to identify recurring patterns and underlying mechanisms and constraints on ecosystem structure (e.g. Elton I927, Lindeman I942, Pimm 1982, Cohen et al. I990, Trites 2003). Many of the conclusions that stem from such studies make intuitive sense, such as the fact that most food chains are size-structured: where most predators are larger than their prey and trophic level typically increases with increasing body size (Pope et al. 1994). Overall, system biomass appears to be proportional to primary production (Pimm I982), and the proportion of species occupying top, intermediate and basal trophic levels appears to be constant across food webs (Cohen 1978). There also appears to be a relatively constant ratio of two to three species of prey for every predator in an ecosystem (Martinez I99I), although numbers of species of prey consumed by each species of predator tends to increase as the size of the food web increases.

The lengths of most chains that form food webs are typically short (two to five links) with maximum reported lengths of eight in tropical shelf seas, 
seven in tropical estuaries and six in oceanic upwelling areas (Christensen \& Pauly I993). Food-chain lengths appear to be a function of both environmental stability and energy-transfer efficiency between trophic levels (Trites 2003). Longer food chains exist associated with stable environments, while shorter food chains exist in less predictable environments (Pimm I99I, Jennings \& Warr 2003). Species at the end of long food chains would be at risk of extinction if the abundance of species lower in the food chain fluctuated severely through natural or anthropogenic causes (fishing). Thus it appears that fisheries have the potential to disrupt the biological structure of food webs, particularly in ecosystems comprised primarily of long food chains.

\section{EFFECTS OF APEX PREDATORS}

A number of the parallels and differences that exist between fisheries and apex marine predators offer additional insights into the effects that commercial fisheries can have on ecosystems. As with fisheries, there is a longheld belief that marine mammals significantly affect prey populations (Gulland I987, Butterworth I992, Tamura 2003). This is best demonstrated by the declines of crabs, abalone and urchin numbers that have followed the re-introductions and range expansions of sea otters (Estes I996). Similarly, declines of sea otters and other marine mammals in the Aleutian Islands and Gulf of Alaska may be the result of 'over-hunting' by killer whales (Estes et al. 1998, Doroff et al. 2003, Springer et al. 2003). As for other observations of the direct effects of marine mammals on ecosystems, examples appear to be lacking. This is probably due to an absence of data on the abundance of prey species prior to the recovery of exploited marine mammal populations - or it might reflect a lack of suitable experimental controls or monitoring of forage species to make proper comparisons and conclusions.

As with trawl fisheries, some apex predators such as walrus and grey whales can influence the turnover of nutrients by feeding on species that live in bottom sediments. Marine mammals can also influence growth rates and the sizes at maturity of their prey - as demonstrated in lakes in Quebec, Canada which are home to land-locked harbour seals that feed on trout. Trout in these lakes are younger and spawn at younger ages than in adjacent lakes without harbour seals (Power \& Gregoire i978). The trout also grow faster and attain smaller sizes in the lakes inhabited by harbour seals.

While there are undoubtedly parallels between the effects of fisheries and those of marine mammals on food chains, there are at least three important differences. One is that mammals and all other species that make up food webs are generally limited by the size of prey they can consume. They 
also tend to be specialized feeders and hence draw their energy from a very limited range of trophic levels (e.g. Fig. 2.3); in contrast, humans can feed on any size of organism at any trophic level. A second major difference between fisheries and apex predators is that predator populations in naturally occurring systems are regulated through density-dependent processes that limit reproduction and survival as prey populations decline; however, there is little to regulate the rate of fishery catches apart from economic incentives, which normally increase (rather than decline) as the species becomes rarer. The third, and perhaps most significant, difference between the two is that stable marine food webs are the result of a long period of natural selection and co-evolution between predators and prey, whereas fisheries represent an abrupt, knife-edged selective force that has potentially destabilizing consequences.

To capture their prey, apex predators have evolved special sensory abilities (e.g. vision and hearing), morphologies (e.g. dentition) and physiologies (e.g. diving and breath-holding abilities) (Trites 2002). They have also evolved specialized feeding behaviours to capture prey that move diurnally up and down the water column, or to capture prey that move seasonally across broad geographic ranges. In response, fish and other cold-blooded species of prey have evolved a number of strategies to increase their chances of survival. One is cryptic coloration, such as flatfish that blend in with the bottom when viewed from above but have white undersides to avoid detection when seen from below against a bright sea surface. Many species of fish, invertebrates and zooplankton take refuge from predators in the deep, dark waters during the day and move towards the surface to feed under the cover of night. Another strategy that some species evoke is predator swamping, such as the large aggregations of spawning salmon and herring which reduce the numerical effect of predators on their prey populations. Schooling is another anti-predator behaviour that creates confusion through the sheer volume of stimuli from a fleeing school, making it difficult for apex predators to actively select and maintain pursuit of single individuals.

In addition to directly affecting the behaviours and life histories of other species, some apex predators may also have indirectly influenced the evolution of non-targeted species in their ecosystems by consuming the predators of these species. One such example of this is the relative lack of chemical defences of kelp and other marine algae against urchin predation in systems that also contained sea otters (Estes I996). Another is the consumption by cod of the potential predators and competitors of their young that has effectively resulted in cod 'cultivating' their young (Walters \& Kitchell 200I). 
Overall, it appears that predator-prey interactions have shaped each others life-history strategies, and potentially those of their competitors as well (Katona \& Whitehead I988, Bowen I997, Trites I997). These mechanisms and adaptive traits have undoubtedly helped to maintain the integrity and stability of marine ecosystems. However, none of these selected characteristics are likely to be effective at maintaining populations targeted by fisheries. In fact, many of the features that have allowed prey to flourish in the face of apex predators now make fish more vulnerable to being caught by fisheries (e.g. schooling behaviour, diurnal movement towards surface light, etc.).

\section{CONCLUSIONS}

Marine ecosystems encompass a broad range of habitat types and harbour a wealth of species and genetic diversity. They consist of dynamic food webs whose species have slowly co-evolved to form the systems present today. Fisheries are a relative latecomer to the evolutionary predator-prey game, and are playing by different sets of rules and with a different set of ultimate consequences. However, the continued growth and expansion of fisheries around the world suggests that there is little appreciation of the effects that fishing has on ecosystems.

On many levels, fisheries have a lot in common with apex predators in that they can reduce the abundance of their prey and can influence the rates of growth and maturity of the species they target. Fisheries can also influence rates of turnover and nutrient cycling. However, the effects of fisheries go well beyond those of other apex predators, due in large part to their capacity to remove large amounts of biomass from the world's oceans and the lack of biological controls or feedback to limit what and how much they take.

Humans are biologically successful because they can feed from all trophic levels and can consume any size of prey. They are also not impeded by low prey abundance. The highly selective nature of fisheries means that they have the potential to cause evolutionary changes in the species they target that may be hard to reverse.

Current understanding of the full indirect effects that major removals by fisheries can have on other components of the ecosystem is poor but is improving with the development of ecosystem models and an emphasis on better monitoring of indicators of ecosystem change. Although not all ecosystems are over-fished, e.g. Alaska (Pew Oceans Commission 2003, US Commission on Ocean Policy 2004), they are an increasing minority rather than the rule given that $75 \%$ of all fished populations are either fully 
exploited, over-exploited or depleted (FAO 2002). Similarly, not all changes that occur in ecosystems are the result of fishing (e.g. Caddy 2000 , Benson $\&$ Trites 2002). However, fishing alone has the capacity to operate outside of the natural rules that govern populations and their ecosystems. In general, large removals by fisheries can have destabilizing effects on marine ecosystems, particularly on systems composed of highly reticulated food webs. Intensive fishing may thus lead to large and long-lasting ecosystem changes, and an inability of heavily fished ecosystems to support abundant, healthy populations of apex predators.

\section{ACKNOWLEDGEMENTS}

Support for V. C. and D. P. was made possible by the Sea Around Us Project, which was initiated and funded by the Pew Charitable Trust; D. P. also received support from Canada's National Science and Engineering Research Council. A. W. T. was supported by the North Pacific Marine Science Foundation through the North Pacific Universities Marine Mammal Research Consortium.

\section{REFERENCES}

Agardy, T. (2000). Effects of fisheries on marine ecosystems: a conservationist's perspective. ICES J. Mar. Sci., 57, 76I-5.

Alonzo, S. H., Switzer, P. V. \& Mangel, M. (2003). An ecosystem-based approach to management: using individual behaviour to predict the indirect effects of Antarctic krill fisheries on penguin foraging. J. Appl. Ecol., 40, 692-702.

Arias-Gonzalez, J. E., Nunez-Lara, E., Gonzalez-Salas, C. \& Galzin, R. (2004). Trophic models for investigation of fishing effect on coral reef ecosystems. Ecol. Model., I72, I97-212.

Benson, A. J. \& Trites, A. W. (2002). Ecological effects of regime shifts in the Bering Sea and eastern North Pacific Ocean. Fish Fisher., 3, 95-II3.

Bianchi, G., Gislason, H., Graham, K. et al. (2000). Impact of fishing on size composition and diversity of demersal fish communities. ICES J. Mar. Sci., 57, $55^{8}-7$ I.

Botsford, L. W., Castilla, J. C. \& Peterson, C. H. (I997). The management of fisheries and marine ecosystems. Science, 277, 509-15.

Bowen, W. D. (I997). Role of marine mammals in aquatic ecosystems. Mar. Ecol. Prog. Ser., I58, 267-74.

Bredesen, E. L. (2003). Krill and the Antarctic: finding the balance. M.Sc. thesis, University of British Columbia, Canada.

Butterworth, D. S. (I992). Will more seals result in reduced fishing quotas? S. Afr. J. Sci., 88, 4I4-16.

Caddy, J. F. (2000). Marine catchment basin effects versus impacts of fisheries on semi-enclosed seas. ICES J. Mar. Sci., 57, 628-40. 
Christensen, V. (1998). Fishery-induced changes in a marine ecosystem: insight from models of the Gulf of Thailand. J. Fish Biol., 53, I28-42.

Christensen, V. \& Pauly, D. (I993). Flow characteristics of aquatic ecosystems. In Trophic Models of Aquatic Ecosystems, eds. V. Christensen \& D. Pauly. ICLARM Conference Proceedings 26. Manila, Philippines: ICLARM, pp. 338-52.

Christensen, V. \& Walters, C. J. (2004). Ecopath with Ecosim: methods, capabilities and limitations. Ecol. Model., I72, I09-39.

Christensen, V., Garces, L. R., Silvestre, G. T. \& Pauly, D. (2003a). Fisheries impact on the South China Sea Large Marine Ecosystem: a preliminary analysis using spatially-explicit methodology. In Assessment, Management and Future Directions for Coastal Fisheries in Asian Countries, eds. G. T. Silvestre, L. R. Garces, I. Stobutzki, et al. World Fish Center Conference Proceedings 67. Penang, Malaysia: WorldFish Centre, pp. 5I-62.

Christensen, V., Guénette, S., Heymans, J. J. et al. (2003b). Hundred-year decline of North Atlantic predatory fishes. Fish Fisher., 4, I-24.

Christensen, V., Amorim, P., Diallo, I. et al. (2004). Trends in fish biomass off Northwest Africa, 1960-2000. In Marine Fisheries, Ecosystems, and Societies in West Africa: Half a Century of Change, eds. P. Chavance, M. Ba, D. Gascuel, J. M. Vakily \& D. Pauly. Paris: Institut de Recherche pour le Development; Brussels: European Commission, pp. 377-86.

Cohen, J. E. (1978). Food Webs and Niche Space. Princeton, NJ: Princeton University Press.

Cohen, J. E., Briand, F. \& Newman, C. M. (I990). Community Food Webs: Data and Theory. New York: Springer-Verlag.

Cox, S. P., Essington, T. E., Kitchell, J. F. et al. (2002). Reconstructing ecosystem dynamics in the central Pacific Ocean, I952-I998. II. A preliminary assessment of the trophic impacts of fishing and effects on tuna dynamics. Can. J. Fish. Aquat. Sci., 59, I736-47.

Daskalov, G. M. (2002). Overfishing drives a trophic cascade in the Black Sea. Mar. Ecol. Prog. Ser., 225, 53-63.

Doroff, A. M., Estes, J. A., Tinker, M. T., Burn, D. M. \& Evans, T. J. (2003). Sea otter population declines in the Aleutian archipelago. J. Mamm., 84, 55-64.

Elton, C. (1927). Animal Ecology. London: Sidgwick and Jackson.

Estes, J. A. (I996). The influence of large, mobile predators in aquatic food webs: examples from sea otters and kelp forests. In Aquatic Predators and their Prey, eds. S. P. R. Greenstreet \& M. L. Tasker. Oxford, UK: Fishing News Books, pp. 65-72.

Estes, J. A., Tinker, M. T., Williams, T. M. \& Doak, D. F. (1998). Killer whale predation on sea otters linking oceanic and nearshore ecosystems. Science, 282, 473-6.

FAO (Food and Agriculture Organization) (2002). The State of World Fisheries and Aquaculture. Rome, Italy: Fisheries Department, Food and Agriculture Organization.

Garrison, L. P. \& Link, J. S. (2000). Fishing effects on spatial distribution and trophic guild structure of the fish community in the Georges Bank region. ICES J. Mar. Sci., 57, 723-30.

Goni, R. (I998). Ecosystem effects of marine fisheries: an overview. Ocean Coastal Managmt, 40, 37-64. 
Gulland, J. A. (I987). The impact of seals on fisheries. Mar. Policy, II, I96-204.

Heino, M. \& Godo, O. R. (2002). Fisheries-induced selection pressures in the context of sustainable fisheries. Bull. Mar. Sci., 70, 639-56.

Hermsen, J. M., Collie, J. S. \& Valentine, P. C. (2003). Mobile fishing gear reduces benthic megafaunal production on Georges Bank. Mar. Ecol. Prog. Ser., 26o, 97-108.

Hutchings, J. A. (2000). Collapse and recovery of marine fishes. Nature, 406, $882-5$.

(2004). The cod that got away. Nature, 428, 899-9oo.

Hutchinson, W. F., Oosterhout, C. van, Rogers, S. I. \& Carvalho, G. R. (2003). Temporal analysis of archived samples indicates marked genetic changes in declining North Sea cod (Gadus morhua). Proc. R. Soc. Lond. B, 270, 2I25-32.

Jackson, J. B. C., Kirby, M. X., Berger, W. H. et al. (200I) Historical overfishing and the recent collapse of coastal ecosystems. Science, 293, 629-38.

Jennings, S. \& Warr, K. J. (2003). Smaller predator-prey body size ratios in longer food chains. Proc. R. Soc. Lond. B, 270, I4I3-I7.

Jennings, S., Dinmore, T. A., Duplisea, D. E., Warr, K. J. \& Lancaster, J. E. (200I). Trawling disturbance can modify benthic production processes. J. Anim. Ecol., 70, 459-75.

Katona, S. \& Whitehead, H. (1988). Are cetacea ecologically important? Oceanogr. Mar. Biol. Annu. Rev., 26, 553-68.

Koslow, J. A., Boehlert, G. W., Gordon, J. D. M. et al. (2000). Continental slope and deep-sea fisheries: implications for a fragile ecosystem. ICES J. Mar. Sci., 57, $548-57$.

Law, R. (2000). Fishing, selection, and phenotypic evolution. ICES J. Mar. Sci., 57, 659-68.

Lindeman, R. L. (I942). The trophic-dynamic aspect of ecology. Ecology, 23, 399-4I8.

Martinez, N. D. (I99I). Artifacts or attributes? Effects of resolution on the Little Rock Lake food web. Ecol. Monogr., 6r, 367-92.

Merrett, N. R. \& Haedrich, R. L. (1997). Deep Sea Demersal Fish and Fisheries. London: Chapman and Hall.

Myers, R. A. \& Worm, B. (2003). Rapid worldwide depletion of predatory fish communities. Nature, 423, 280-3.

Olsen, E. M., Heino, M., Lilly, G. R. et al. (2004). Maturation trends indicative of rapid evolution preceded the collapse of northern cod. Nature, 428, 932-5.

Pauly, D. (I980). A new methodology for rapidly acquiring basic information on tropical fish stocks: growth, mortality and stock-recruitment relationships. In Stock Assessment for Tropical Small-Scale Workshop, 19-21 September, 1979, University of Rhode Island, eds. S. Saila \& P. Roedel. Kingston, RI: International Center for Marine Resources Development, pp. 154-72.

Pauly, D., Christensen, V., Dalsgaard, J., Froese, R. \& Torres, F., Jr (I998a). Fishing down marine food webs. Science, 279, 860-3.

Pauly, D., Trites, A. W., Capuli, E. \& Christensen, V. (I998b). Diet composition and trophic levels of marine mammals. J. Mar. Sci., 55, 467-8I.

Pauly, D., Christensen, V., Guénette, S. et al. (2002). Towards sustainability in world fisheries. Nature, 418, 689-95. 
Pauly, D., Alder, J., Bennett, E. et al. (2003). The future for fisheries. Science, 302, I359-6I.

Pew Oceans Commission (2003). America's Living Oceans: Charting a Course for Sea Change. A Report to the Nation. May 2003. Arlington, VA: Pew Oceans Commission.

Pimm, S. L. (1982). Food Webs. London: Chapman and Hall. (I99I). The Balance of Nature? Chicago, IL: University of Chicago Press.

Pope, J. G., Shepherd, J. G. \& Webb, J. (I994). Successful surf-riding on size spectra: the secret of survival in the sea. Phil. Trans. R. Soc., 343, 4I-9.

Power, G. \& Gregoire, J. (I978). Predation by freshwater seals on the fish community of Lower Seal Lake, Quebec. J. Fish. Res. Board Can., 35, 844-50.

Reiss, M. J. (1989). The Allometry of Growth and Reproduction. Cambridge, UK: Cambridge University Press.

Rochet, M. J. (I998). Short-term effects of fishing on life-history traits of fishes. ICES J. Mar. Sci., 55, 37I-9I.

Sanchez, F. \& Olaso, I. (2004). Effects of fisheries on the Cantabrian Sea shelf ecosystem. Ecol. Model., I72, I5I-74.

Springer, A. M., Estes, J. A., Vliet, G. B, van et al. (2003). Sequential megafaunal collapse in the North Pacific Ocean: an ongoing legacy of industrial whaling? Proc. Natl Acad. Sci. U. S. A., Iоo, I2 223-8.

Tamura, T. (2003). Regional assessments of prey consumption and competition by marine cetaceans in the world. In Responsible Fisheries in the Marine Ecosystem, eds. M. Sinclair \& G. Valdimarsson. Rome, Italy: Food and Agriculture Organization; Wallingford, UK: CABI Publishing, pp. I43-70.

Tasker, M. L., Camphuysen, C. J., Cooper, J. et al. (2000). The impacts of fishing on marine birds. ICES J. Mar. Sci., 57, 53I-47.

Trippel, E. A. (I995). Age at maturity as a stress indicator in fisheries. Bioscience, 45, 759-71.

Trites, A. W. (1997). The role of pinnipeds in the ecosystem. In Pinniped Populations, Eastern North Pacific: Status, Trends and Issues, eds. G. Stone, G. Goebel \& S. Webster. Boston, MA: New England Aquarium, Conservation Department, pp. 3I-9.

(200I). Marine mammal trophic levels and interactions. In Encyclopedia of Ocean Sciences, eds. J. Steele, S. Thorpe \& K. Turekian. London: Academic Press, pp. I628-33.

(2002). Predator-prey relationships. In Encyclopedia of Marine Mammals, eds, W. F. Perrin, B. Wursig \& H. G. M. Thewissen. San Diego, CA: Academic Press, pp. 994-7.

(2003). Food webs in the ocean: who eats who and how much? In Responsible Fisheries in the Marine Ecosystem, eds. M. Sinclair \& G. Valdimarsson. Rome, Italy: Food and Agriculture Organization, Rome; Wallingford, UK: CABI Publishing, pp. 125-43.

Trites, A. W., Christensen, V. \& Pauly, D. (I997). Competition between fisheries and marine mammals for prey and primary production in the Pacific Ocean. J. Northw. Atl. Fish. Sci., 22, I73-87.

Trites, A. W., Livingstone, P., Mackinson, S. et al. (I999). Ecosystem Change and the Decline of Marine Mammals in the Eastern Bering Sea: Testing the Ecosystem Shift 
and Commercial Whaling Hypotheses. Fisheries Centre Research Reports 7(I). Vancouver, Canada: Fisheries Centre.

Trites, A. W., Bredesen, E. L. \& Coombs, A. P. (2004). Whales, whaling and ecosystem change in the Antarctic and Eastern Bering Sea: insights from ecosystem models. In Investigating the Roles of Cetaceans in Marine Ecosystems. CIESM Workshop Monographs 25. Monaco: CIESM, pp. 85-92.

US Commission on Ocean Policy (2004). An Ocean Blueprint for the 21st Century. Final report of the US Commission on Ocean Policy, Washington, DC.

Walters, C. \& Kitchell, J. F. (200I). Cultivation/depensation effects on juvenile survival and recruitment: implications for the theory of fishing. Can. J. Fish. Aquat. Sci., 58, 39-50.

Walters, C. \& Maguire, J. J. (1996). Lessons for stock assessment from the northern cod collapse. Rev. Fish Biol. Fish., 6, I25-37.

Walters, C. J., Christensen, V. \& Pauly, D. (I997). Structuring dynamic models of exploited ecosystems from trophic mass-balance assessments. Rev. Fish Biol. Fish., 7, 139-72.

Watson, R. \& Pauly, D. (200I). Systematic distortions in world fisheries catch trends. Nature, 4I4, 534-6.

Zwanenburg, K. C. T. (2000). The effects of fishing on demersal fish communities of the Scotian Shelf. ICES J. Mar. Sci., 57, 503-9. 